NBER WORKING PAPER SERIES

INCENTIVES AND WORKER BEHAVIOR:

SOME EVIDENCE

Andrew Weiss

Working Paper No. 2194

NATIONAL BUREAU OF ECONOMIC RESEARCH

1050 Massachusetts Avenue

Cambridge, MA 02138

March 1987

The research reported here is part of the NBER's research program in Labor studies. Any opinions expressed are those of the author and not those of the National Bureau of Economic Research. 
NBER Working Paper \#2194

March 1987

Incentives and Worker Behavior: Some Evidence.

\section{$\underline{\text { ABSTRACT }}$}

This paper is concerned with three types of incentive programs. First, individual wage incentives that cause a worker's efforts to have a major effect on his pay. Second, group incentives in which the pay of an individual is determined by the output of a group of workers-a group can be as small as a four member work team or as large as the whole firm. Finally, seniority based payment schemes in which the pay of a worker rises rapidly with his tenure with the firm. We show that these payment schemes have the effects in practice that we would predict from optimizing behavior by workers.

We find that group incentives tend to compress the productivity distribution of workers. This is because the relative performance of the most productive workers tends to fall, and the most and least productive workers have relatively high quit rates when workers are paid on group incentives. We also present evidence that suggests that the low quit rates in large Japanese firms may be due to steep wage-tenure profiles in those firms.

Andrew Weiss Bell Communications Research Morristown, NJ 07960 


\title{
INCENTIVES AND WORKER BEHAVIOR: SOME EVIDENCE
}

\author{
Andrew Weiss \\ Bell Communications Research \\ Morristown, New Jersey 07960
}

This paper is concerned with three types of incentive programs. First, individual wage incentives that cause a worker's efforts to have a major effect on his pay. Second, group incentives in which the pay of an individual is determined by the output of a group of workers ... a group can be as small as a four member work team or as large as the whole firm. Finally, seniority based payment schemes in which the pay of a worker rises rapidly with ais tenure with the firm. We shall examine whether these payment schemes have the effects in practice that we would predict from optimizing behavior by workers.

\section{AIMS OF INCENTIVE PROGRAMS}

Individual incentives are chosen to motivate employees to work hard and to help the firm retain its most able workers. Because each employee is paid in accordance with his own output, a payment schedule can be chosen to induce the optimal level of effort on the part of employees. In addition, since this wage schedule typically results in substantial pay differences between the top and bottom deciles of workers by ability, the more able workers are less likely to quit and the less able workers more likely to quit than if each received the same wage. Unfortunately, individual wage incentives also have significant drawbacks. Workers are not motivated to cooperate with one another, and serious moral problems 
(and grievance procedures in unionized plants) can result from inequalities in the payment schedules across jobs. Consequently, considerable resources must be allocated to evaluating jobs.

Often workers spend time waiting for parts or have their output hindered by faulty equipment. Under individual wage incentives managerial decisions about the impact of these "special conditions" on worker performance may cause friction and result in grievances.

Finally, and perhaps most important, workers may view technological innovations as providing management with an opportunity to tighten rates. The threat posed by any single innovation to an individual worker is greatest if that worker is paid price-rate and the technology affects his job. Hence, resistance to new technology is likely to be greatest in firms using individual wage incentives.

Group incentives avoid many of these drawbacks, but at the expense of less motivation for high effort and lower rewards to high performance workers. For any payment schedule, the larger is the group, the lower is the motivation for an individual worker to exert himself: If the average worker in a 100 member group were to double his output, the output of the group would only rise by only $1 \%$, and for any reasonable pay schedule the individual's earnings would not be significantly affected. Similarly, because the most and least able workers within each group receive the same wages, those pay differences that help firms retain their most able workers are effectively eliminated. On the other hand, group incentives encourage co-operation among members of the same group (especially if groups are small) and reduce friction over perceived inequities in rates (tight rates 
for any one job have only a trivial effect on the group wage incentive of workers assigned to that job).

Although wage incentives are generally thought of as payment systems that link the output of workers to their pay, wages can have incentive effects even when pay is unaffected by output. For example, pay schedules in which earnings or the value of pensions increase rapidly with seniority provide strong incentives for workers to stay with the firm. In this case the behavior that is being affected by the incentive mechanism is the quit rate of workers.

We shall examine the effect of piece-rate, group wage incentives and seniority based wages on the output and quit rates of workers.

\section{GROUP VS. INDIVIDUAL INCENTIVES}

The evidence in this section comes from three plants of a large electronics manufacturer based in the U.S. Because the same patterns were observed at all three locations, we only present data from the largest of the three plants.

The firm pays its workers on a non-linear individual piece-rate schedule when they are first hired, and uses a group incentive pay system for its experienced workers. The initial piece-rate schedule provides significant financial incentives for workers to exert themselves. For a worker performing at $60 \%$ of the expected output on his job, a $1 \%$ increase in his output increases his pay by $.7 \%$. For a worker performing at at $115 \%$ of expected output, a $1 \%$ increase in output increases his pay by $1.2 \%$. Once a worker achieves $83.5 \%$ of the expected output for his job he is placed in a pay group in which his pay is proportional to the out- 
put of the group. The vast majority of workers are on group incentives by their 3rd month with this firm. The average pay group has 126 members. Thus, for experienced workers there is almost no direct financial reward for high output.

By examining the change in the output of workers as they switch from individual to group incentives we can obtain a measure of the relative impact of individual and group incentives on performance. By comparing group incentives with individual incentives in the same plant, we avoid many of the drawbacks of previous studies of the effects of incentives on worker behavior. In particular we ensure:

a) that changes in payment schedules are not associated with radically different supervision (few of the workers changed supervisors when they went from individual to group incentives) and

b) that the observed effects of individual incentives are not due to better monitoring of output under individual incentives. (Output under a measured daywork system can be as much as $20 \%$ greater than the output under the same time-rate pay system but without careful records of individual output.)

Insert Figure 1 Here

As was mentioned, in the firm we're studying all newly hired production workers are paid on individual incentives. By their fourth month on the job almost all of these workers are on group incentives. 
In Figure 1 we plot the change in output from their first to fourth month on the job for newly hired production workers. These workers were ordered on the horizontal axis according to their normalized output in the first month. ${ }^{1}$ Thus the circled dot denotes a worker whose normalized output in the first month was approximately $205 \%$ of the expected level for his job and whose output in month 4 was approximately $120 \%$ of the level expected for a fully trained worker on his job. (All the workers in Figure 1 had jobs requiring fewer than 4 months experience in order to be fully trained. After the fourth month we did not discern any increase in physical output on these jobs.)

As can be seen almost all the workers whose first month performance was above the median decreased thsir output between months one and four. On the other hand, only half of the low performing workers decreased their output between months 1 and 4 .

This effect is accentuated if we focus on workers whose first month output was more than $10 \%$ above or below the median. Among workers whose first month output was more than $10 \%$ below the median, $79 \%$ increased their output. Out of the 208 workers whose first month output was more than $10 \%$ above the median only 1 worker increased his output.

These effects are unlikely to be due to random noise or measurement error causing convergence toward the mean. As we see in Figures $2 a$ and $2 b$, among workers who completed their training within 4 months the variance of output is

\footnotetext{
${ }^{1}$ Recorded output was normalized by the industrial engineers to adjust for differences in the expected output of experienced workers on the different jobs and for differences in the difficulty of learning the different jobs.
} 
much lower during their 4 th month on the job than during their first month. This same pattern held at the two other locations of the firm which we studied.

\section{Insert Figure 2 Here}

It is of course possible that the industrial engineers miscalculated the difficulty of learning different tasks. These errors would be likely to increase the variance of recorded normalized first month output. When we estimated the effect of the reported time needed to learn a job on normalized first month output, we found that, after correcting for the personal characteristics of the workers, the workers that were assigned to jobs that took longer to learn reported higher levels of normalized first month output. ${ }^{2}$

In Figure 2c we first removed the effects on normalized output of our estimates of the industrial engineer's overassessments of the difficulty of learning complex tasks. We then recorded these adjusted output levels as a percentage of the man of the recalculated output levels. (Thus we forced the mean of the renormalized output levels to be equal to 100. For experienced workers who are off the learning curves for their jobs the mean normalized output level as computed by the industrial engineering force is 100.2 .)

Comparing Figure 2c with Figure 2a it is apparent that our renormalization decreases the variance in the first month output of workers. However, comparing

${ }^{2}$ In the output equation that we estimated, the coefficient of the logarithm of required training on normalized output was 5.6. It is this distortion which we sought to eliminate by the renormalization described below. Workers were randomly assigned to jobs so we did not need to correct for job assignment effects. 
Figure 2c with Figure $2 \mathrm{~b}$ it is also apparent that, even after the renormalization, the variance of the first month output of newly hired workers is still far higher than the variance of the output of those same workers during their fourth month on the job.

The data described in Figure 1 retains its same qualitative features if renormalized output is used as the measure of first month performance rather than the normalized output reported by the industrial engineering force.

Of course, even after performing this renormalization, it is still possible that the wide distribution of the output of newly hired workers relative to the distribution of their output after four months of employment is due to larger measurement errors in calculating the output of the newly hired workers than in calculating the output of experienced workers. ${ }^{3}$

It is also possible that the collapse in the distribution of the output of experienced workers relative to new hires is due to convergence to some "natural" level of performance.

Insert Figure 3 Here

The data presented in Figure 3 casts doubt on these explanations. Figure 3 uses English data from the Industrial Health Research Board to construct the distribution of the output of piece-rate workers on production jobs as a percentage $\overline{3}$ For example, the industrial engineers may be underestimating the difference between the expected output of experienced and inexperienced workers on some jobs while overestimating this difference for other jobs -- on the other hand, their assessments of the relative difficulty of different jobs for experienced workers could be accurate. 
of the mean output of workers on their jobs. This distribution is much wider than the normalized output of experienced workers at any of the plants we studied, a phenomenon which appears inconsistent with either the measurement error for newly hired workers or convergence hypotheses.

This English data, along with the data presented in Figures 1 and 2, suggest that it is the movement of workers from individual to group wage incentives, coupled with the socialization process within the plants we studied, that caused the output of workers to converge to some (artificial?) standard.

Workers whose output is low are exhorted by their supervisors and threatened with dismissal unless they reach a satisfactory output level for their job. Those workers either quit or push themselves to reach the standards. The more able workers, on the other hand, have only trivial financial incentives to achieve high levels of output, and often their co-workers exhort them not to "break the rates." Workers correctly anticipate that exceptionally high performance by one worker will cause management to re-evaluate the expected output for that worker's job. Hence, the most able workers are likely to work less hard than they would under piece-rate pay.

Because of pressures to shirk, the high ability workers may even work at lower levels than they would under an unmonitored wage system where there is no peer pressure not to "break the rates." In another location of this firm, in which there were no wage incentives and little use was made of individual output records, the top decile of workers on a job often performed at more than twice expected the output for their job, while the bottom decile was at $70-80 \%$ of 
expected output. Thus it would appear likely that at least some workers on group wage incentives might be working slower than the pace at which they would be most comfortable.

The firm is accustomed to having few high performance workers and so does not penalize a supervisor for not having any super-stars among his workers. Consequently, supervisors concentrate on either pushing the low performance workers to work harder or to quit, rather than encouraging their most able workers to achieve the high levels of output of which they are capable.

Because group incentives do nct reward high performance, and because promotional opportunities in this plant were nill, we would expect the most able workers to de more likely to quit to work for a firm in which their performance is rewarded either directly through higher pay or indirectly through more rapid promotions.

\section{Insert Figures $4 \mathrm{a}$ and $4 \mathrm{~b}$ Here}

As we can see in Figure $4 \mathrm{~b}$ those workers whose output was highest (the 5 th quintile) are the most likely to quit within their first 18 months on the job. These quits may be due to the attraction of better alternative opportunities at firms where individual output is rewarded, or, alternatively, these quits could be due to discomfort on their present job caused by pressures from their co-workers not to achieve high levels of output.

The least able workers also have higher quit rates than the average workers. For those low ability workers, pressures by their supervisors to achieve an 
"acceptable" output level make their jobs unpleasant. They may also be pressured to quit by supervisors, whose own performance evaluations are strongly affected by low output workers. These effects seem strongest for newly hired workers, so the relatively high quit rates of low ability workers are most noticeable for quits within the first 6 months of employment. The factors inducing the high ability workers to quit seem to take longer to have their full effect. The impact of relatively high quit rates of the most able workers is thus most noticeable for quits within the first 18 months of employment. This general pattern that the best performing and the worst performing workers were most likely to quit was also present in the other plants we studied.

Insert Figure 5 Here

In Figure 5 we see the total effect of the switch from individual to group incentives on the distribution of performance. The distribution has collapsed. By their sixth month on the job there are few workers performing either $10 \%$ above or below the median level. This collapse of the output distribution is due to attrition at both ends of the output distribution and to a slackening of the effort of the more able workers relative to the effort of the less able workers.

Most of the literature on wage incentives has focused on the effects of piecerate type payment schemes on the behavior of workers. However, wages can be linked to aspects of behavior other than output to provide incentives in those areas. 


\section{SENIORITY BASED WAGES}

As we mentioned in Section 1, a firm that wishes to discourage quits could pay wages that rise steeply with seniority. Employees of that firm are paid less than the value of their contribution to output when they are young and more when they are old. Hence, after a few years of employment the worker has a strong incentive to stay with the firm. In effect, the employee has made a loan to the firm that is only fully repaid if the employee remains with the firm until retirement. The size of that loan initially increases as the workers stays longer with the firm. A firm offering wages that rise steeply with seniority would expect to find that its more senior employees are much less likely to quit than are its new kires.

We shall test this hypothesis with data from a large Japanese electronics manufacturer. In that firm the average 50 year old male high school graduate earns 4-1/2 times as much as the average 20 year old male high school graduate. Graphs of the average wage as a function of tenure are presented in Figure 6.

Insert Figures $6 \mathrm{a}$ and $6 \mathrm{~b}$ Here

We also plot the quit rate for different tenure groups. Quits fall rapidly with seniority. This decline in quits is much more dramatic than in the U.S. and is also much greater than in medium sized or small Japanese firms. U.S. and smaller Japanese firms also offer wages that rise less rapidly with seniority than do the wages illustrated in Figure 6. Hence, it would seem that the decline in quits is due to the incentive effect of the steep wage-tenure profiles, rather than to 
worker heterogeneity which would cause quitters to quit early and give a similarly rapid decline of quits with seniority.

$$
\text { Insert Figure } 7 \text { Here }
$$

By reducing quit rates, these steep wage-tenure profiles have indirect effects on other managerial decisions of the firm. In particular, we would expect firms that offer steeper wage-tenure profiles to invest more in recruiting and training their workers -- since those workers will on average stay longer with the firm whose investments are more profitable. The evidence supports this hypothesis. Large Japanese firms that offer wages that rise rapidly with seniority also invest heavily in training and recruiting an elite work force.

\section{To sum up:}

1. When pay groups are large, a group wage incentive program does not adequately motivate the most able workers, nor does it dissuade those workers from quitting.

2. Linking pay to seniority lowers quit rates and increases the pay-off from expenditures on hiring and training workers. 


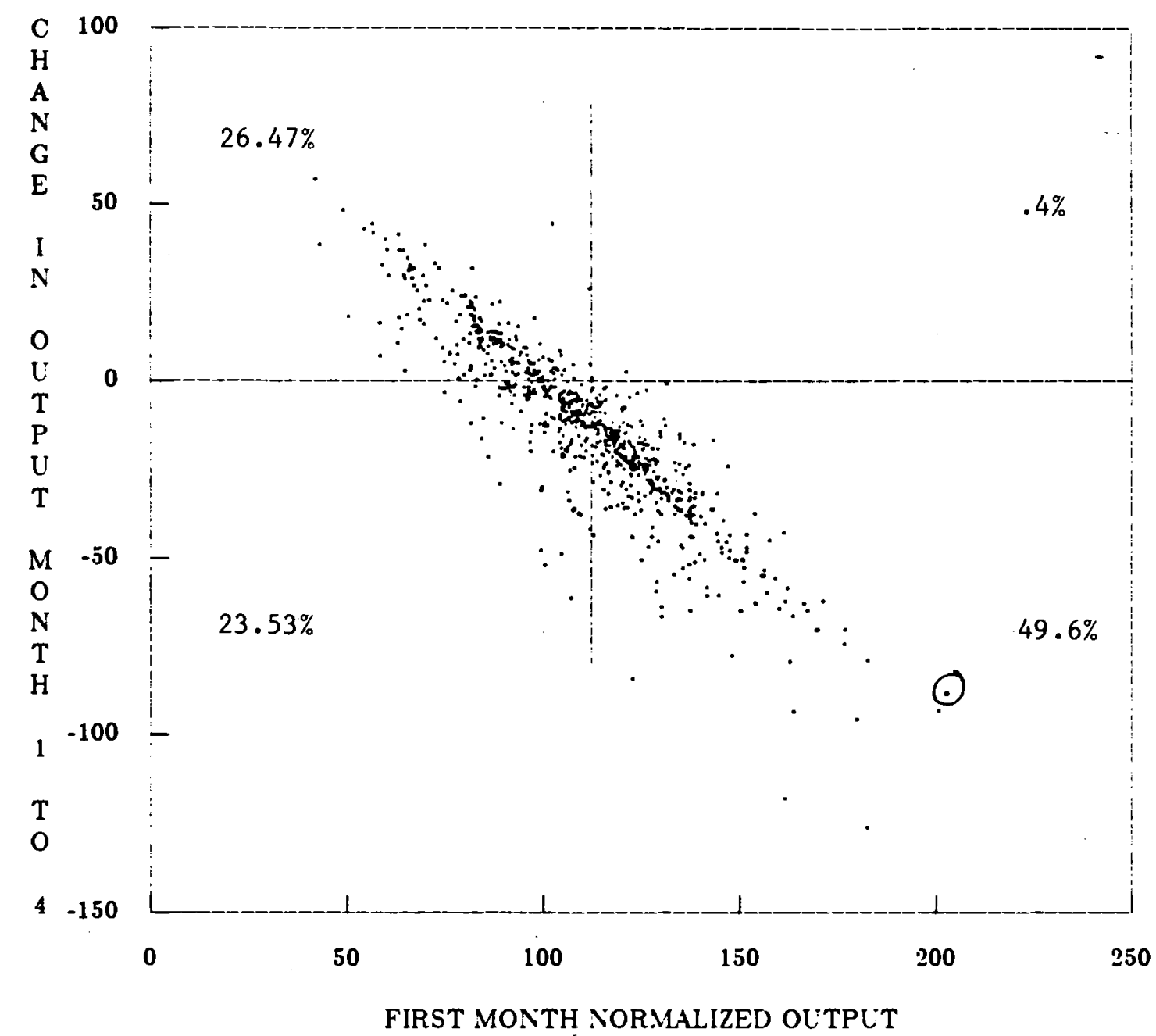

752 OBSERVATIONS

SUBSET: NON-LEARNERS IN MONTH 4

FIGURE 1 


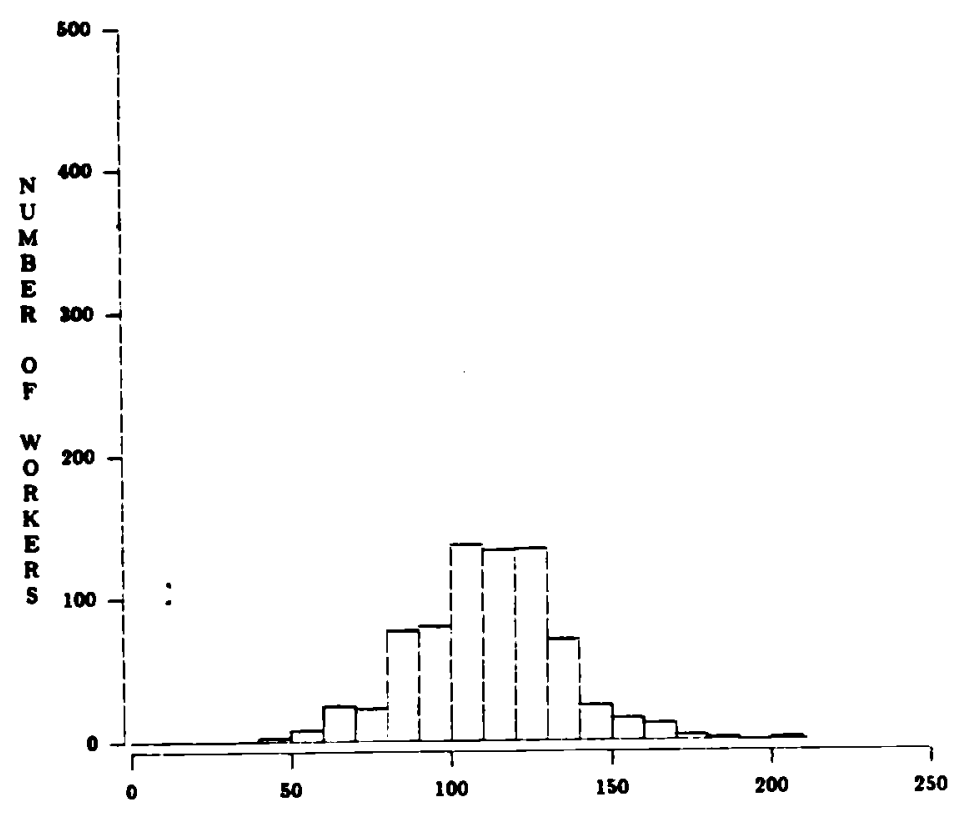

NORMALIZED FIRST MONTH EFFICIENCY

752 Observations

Figure 2a
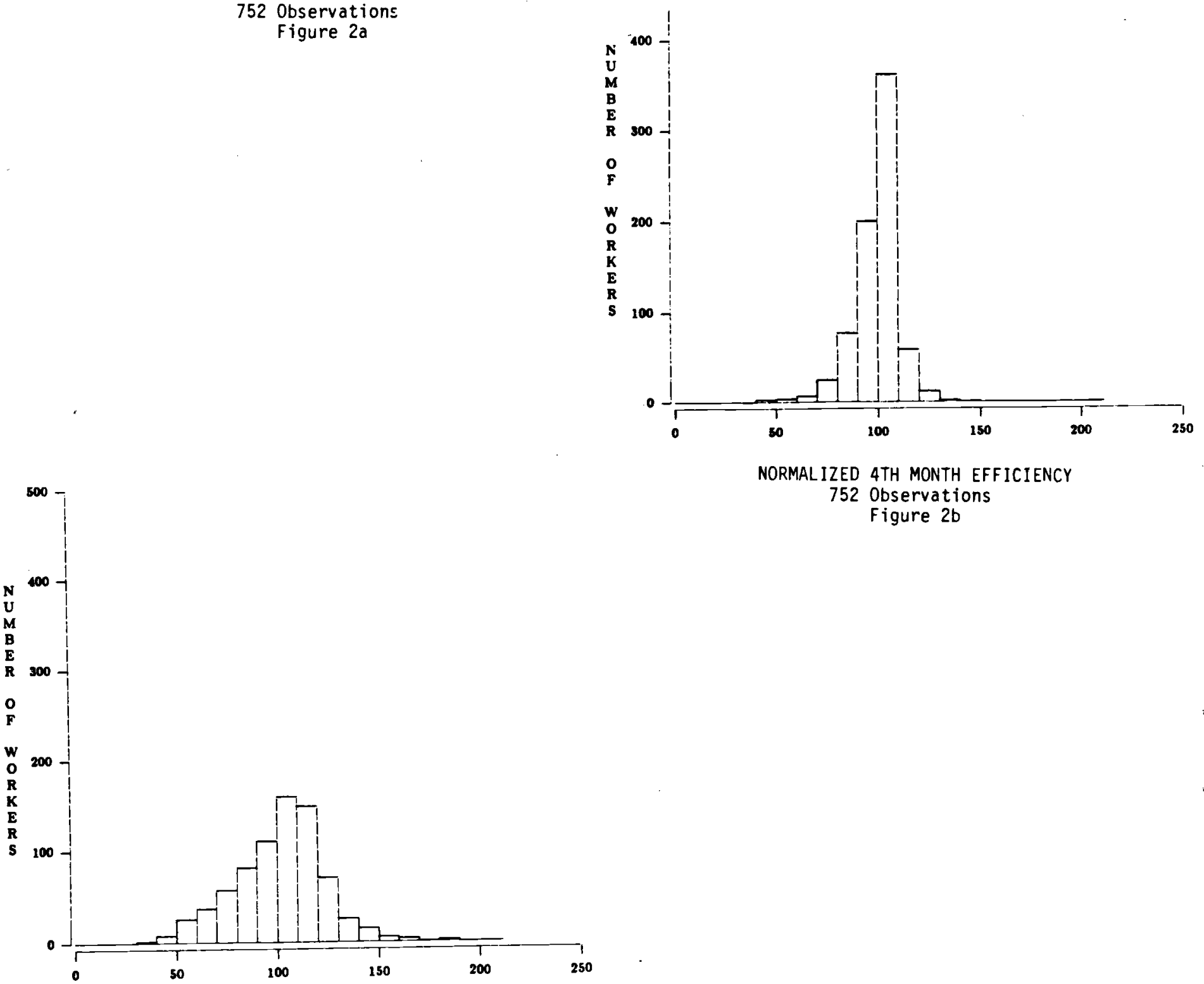

NORMALIZED 4TH MONTH EFFICIENCY

752 Observations

Figure 2b

RENORMALIZED FIRST MONTH EFFICIENCY

ADJUSTED FOR TRAINING DURATION

752 observations

Fiaure 2c 


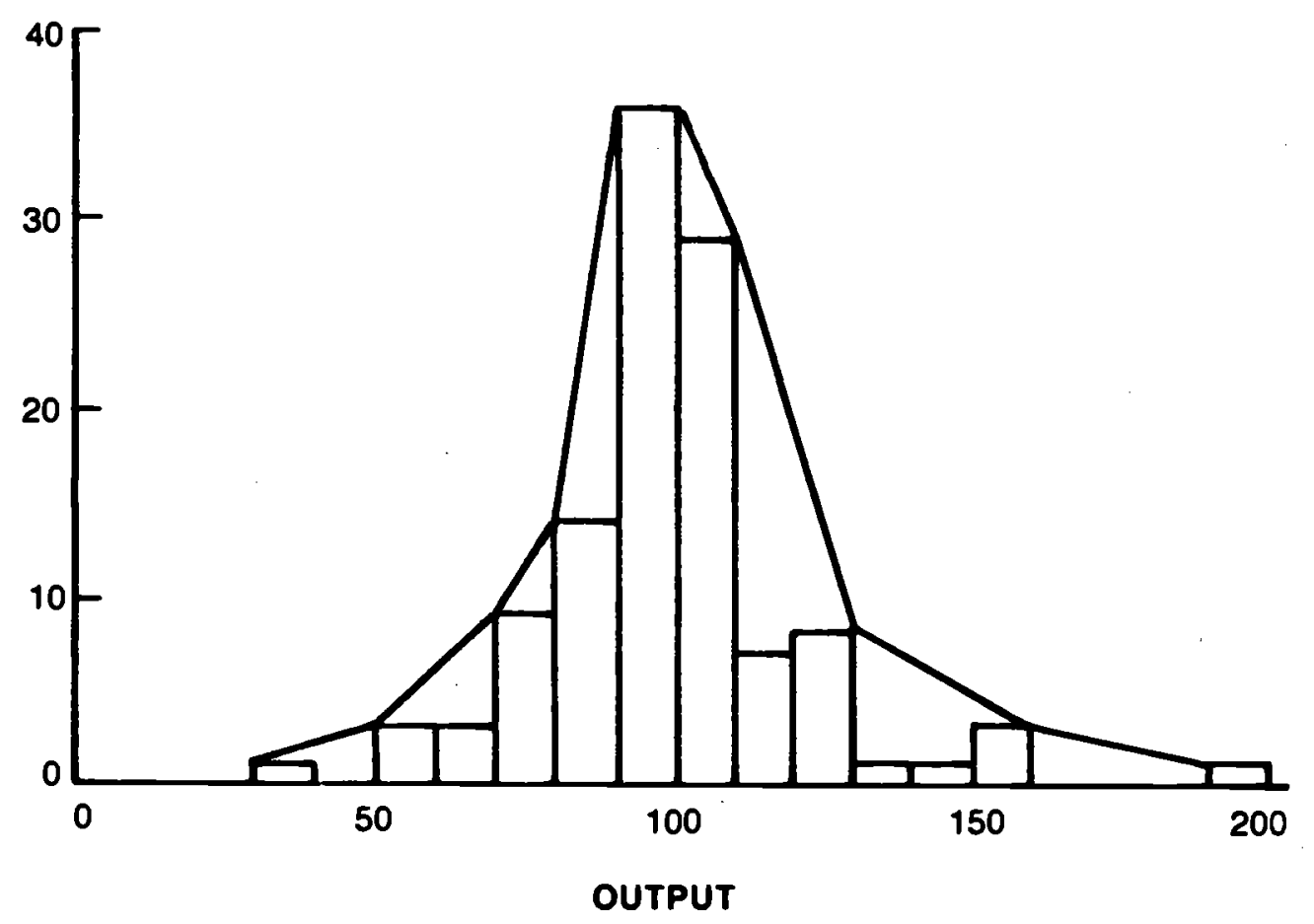

FIGURE 3 

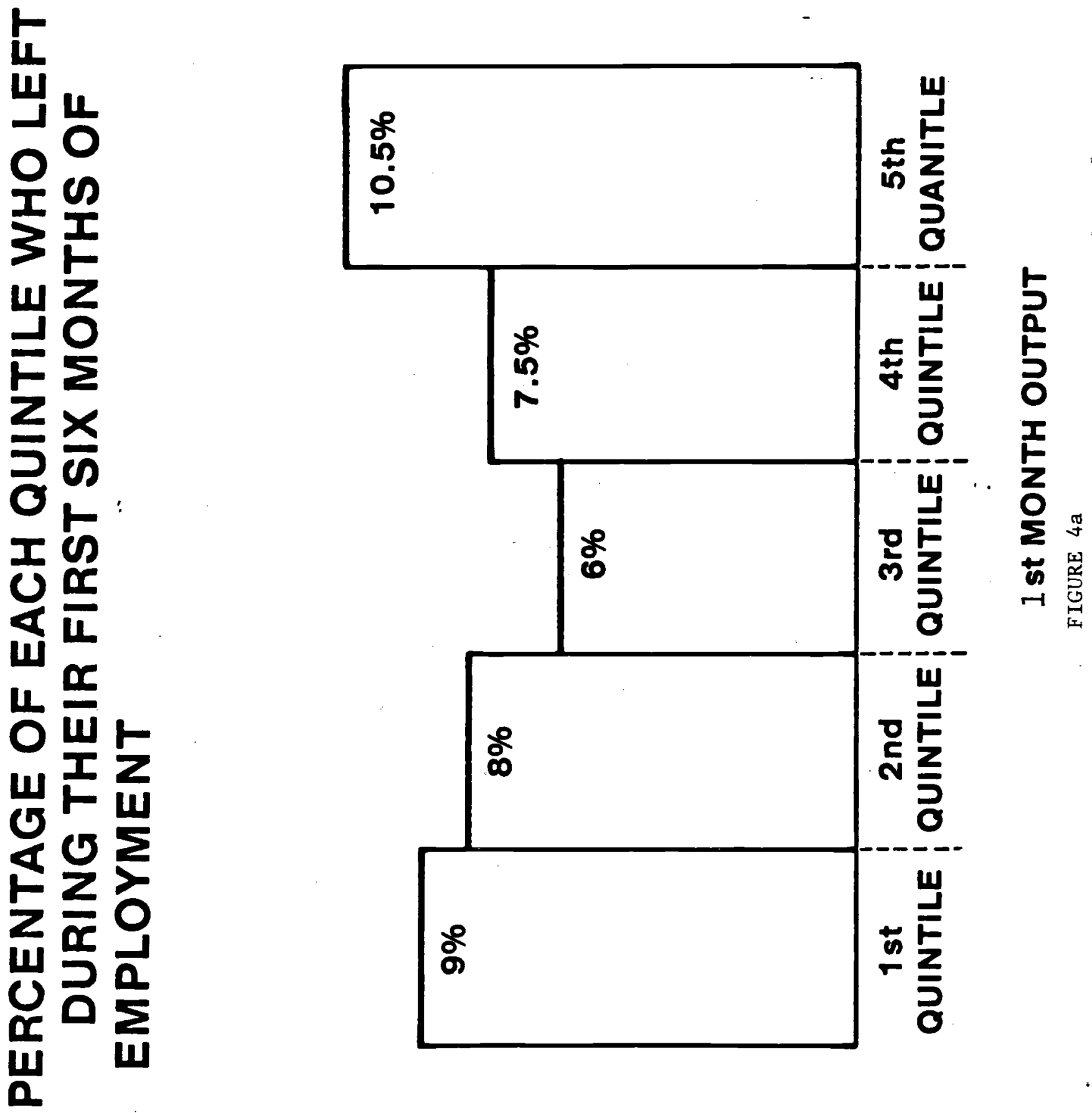


\section{PERCENT AGE OF EACH QUINTILE WHO QUIT WITHIN}

THEIR FIRST 18 MONTHS OF EMPLOYMENT

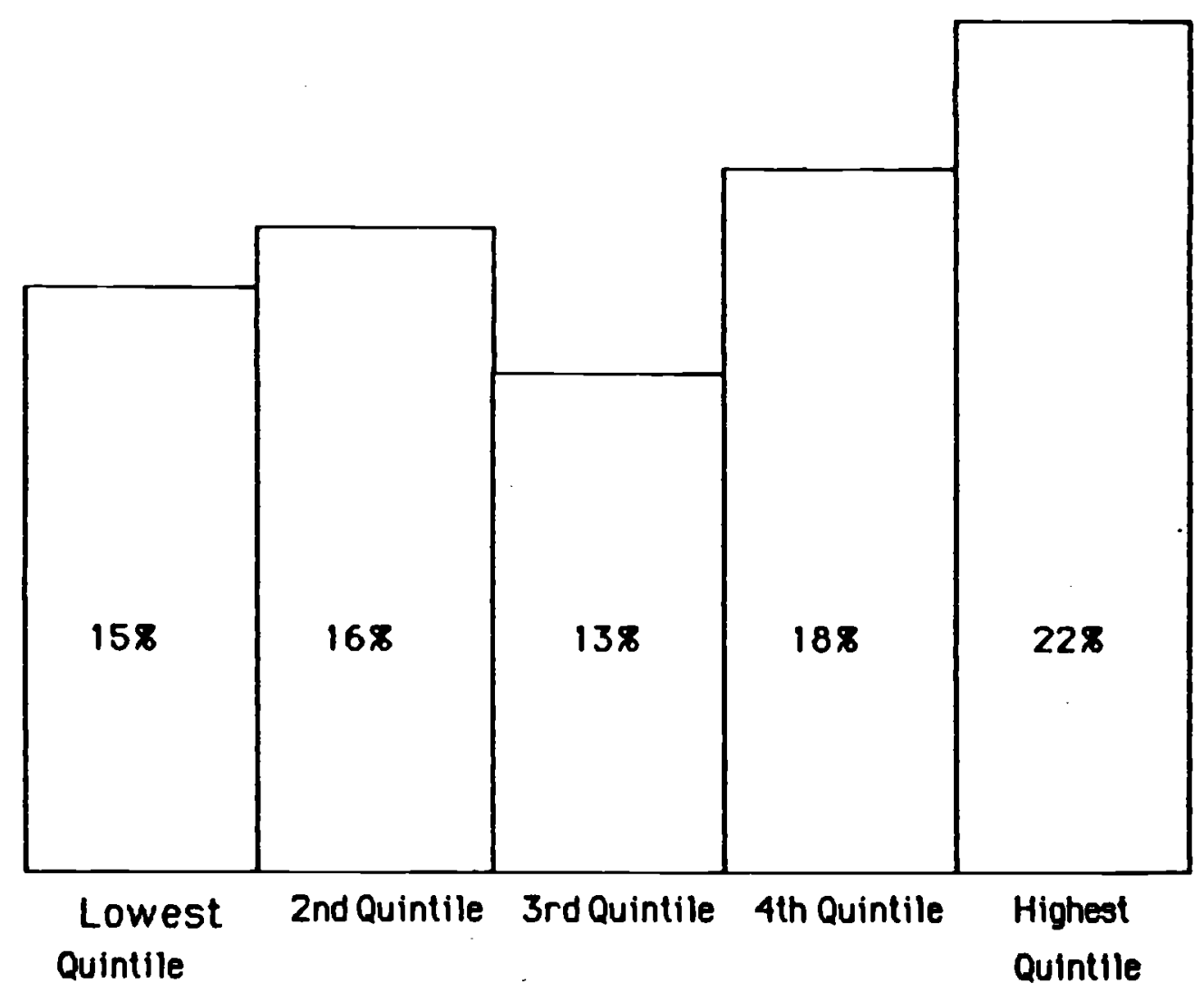

FIRST MONTH OUTPUT

FIGURE 4b 

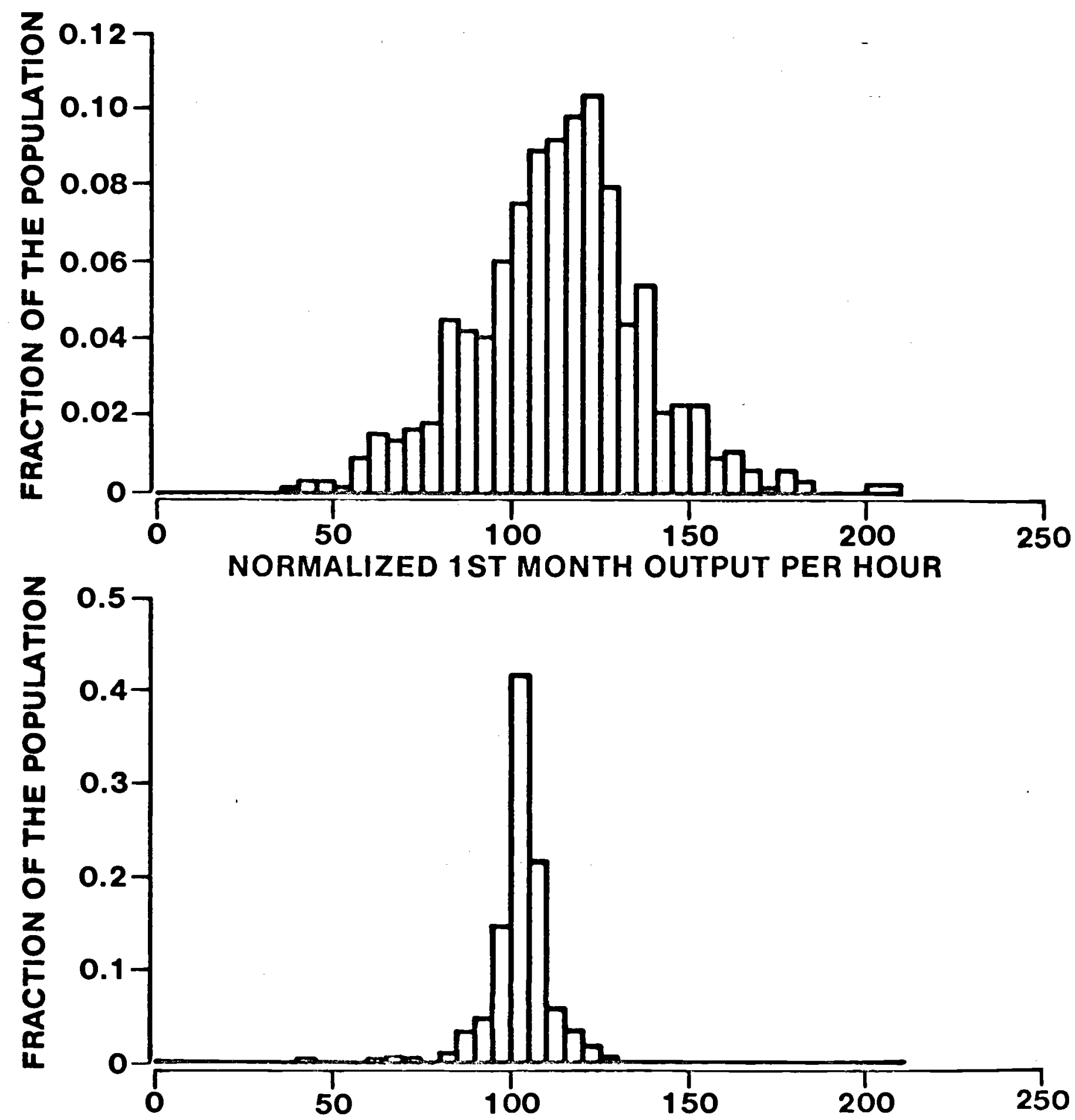

6TH MONTH OUTPUT PER HOUR FOR WORKERS WHO HAVE COMPLETED THEIR TRAINING 


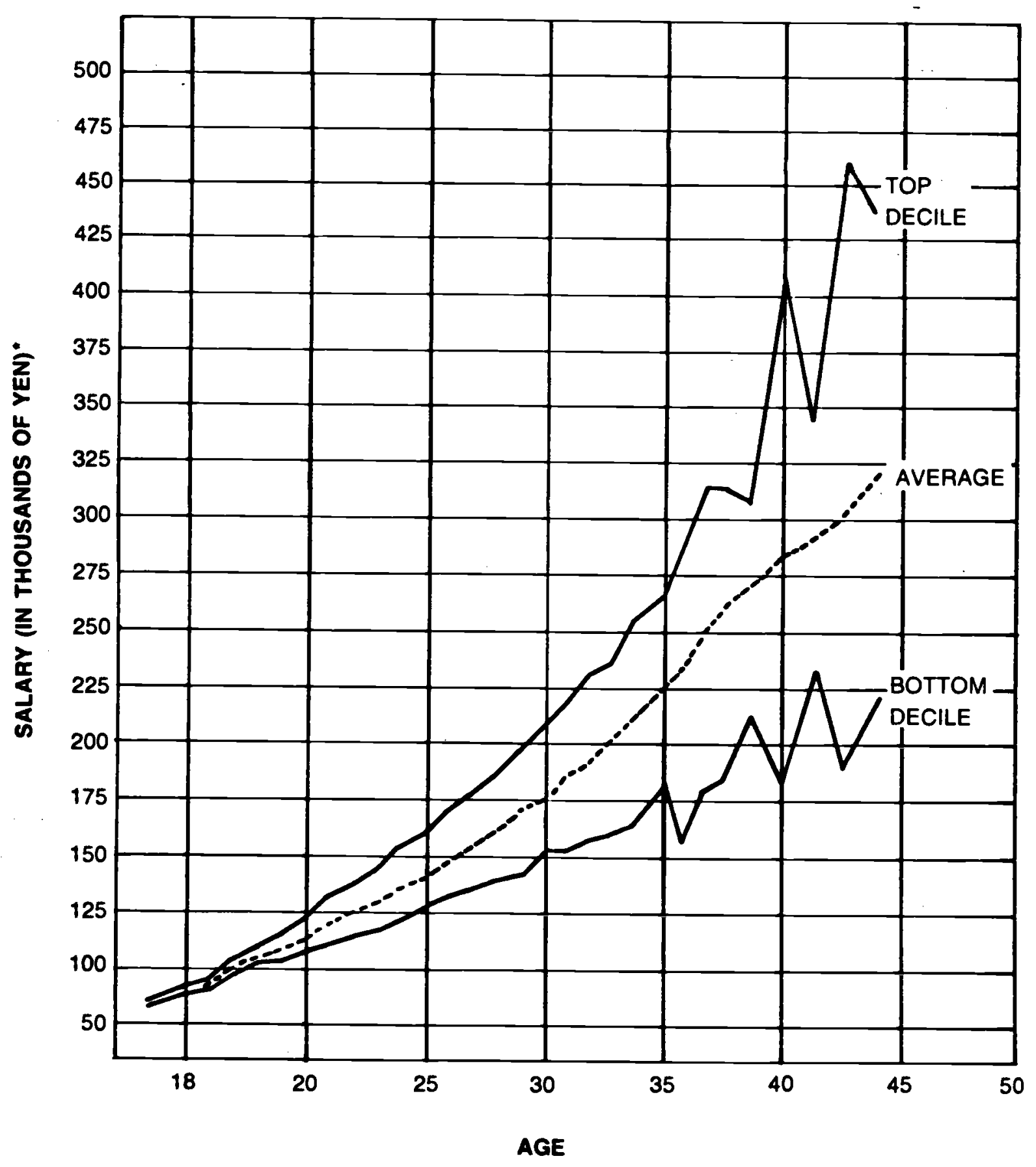

- To get salary in dollars, divide by 235

1981 MONTHLY BASIC SALARY DISTRIBUTION FOR WHITE COLLAR, MALE HIGH SCHOOL GRADUATES BY AGE 


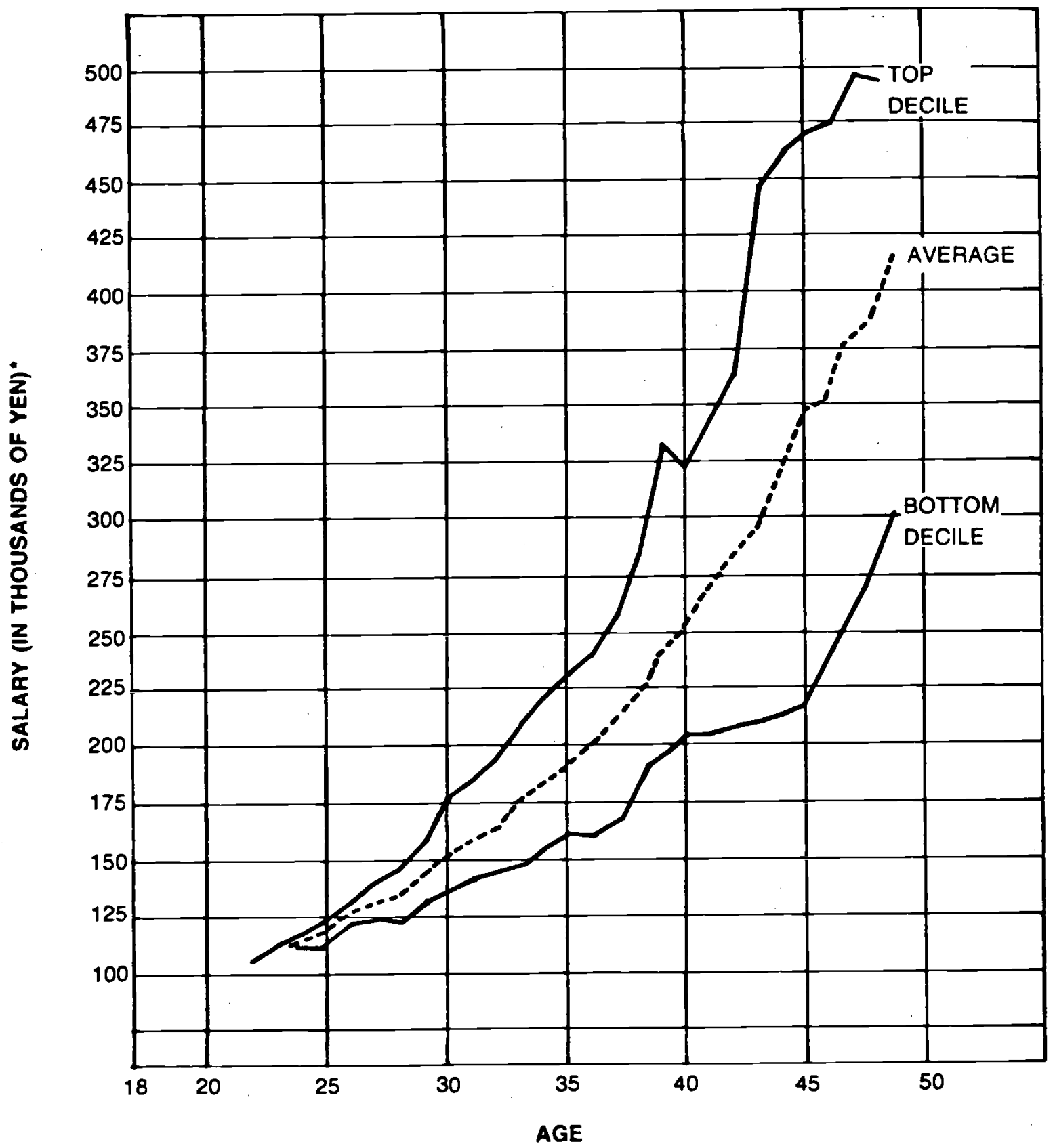

- To get salary in dollars, divide by 235

1981 MONTHLY BASIC SALARY DISTRIBUTION FOR MALE UNIVERSITY GRADUATES BY AGE 
MALE WORKERS AT A LARGE JAPANESE MANUFACTURER

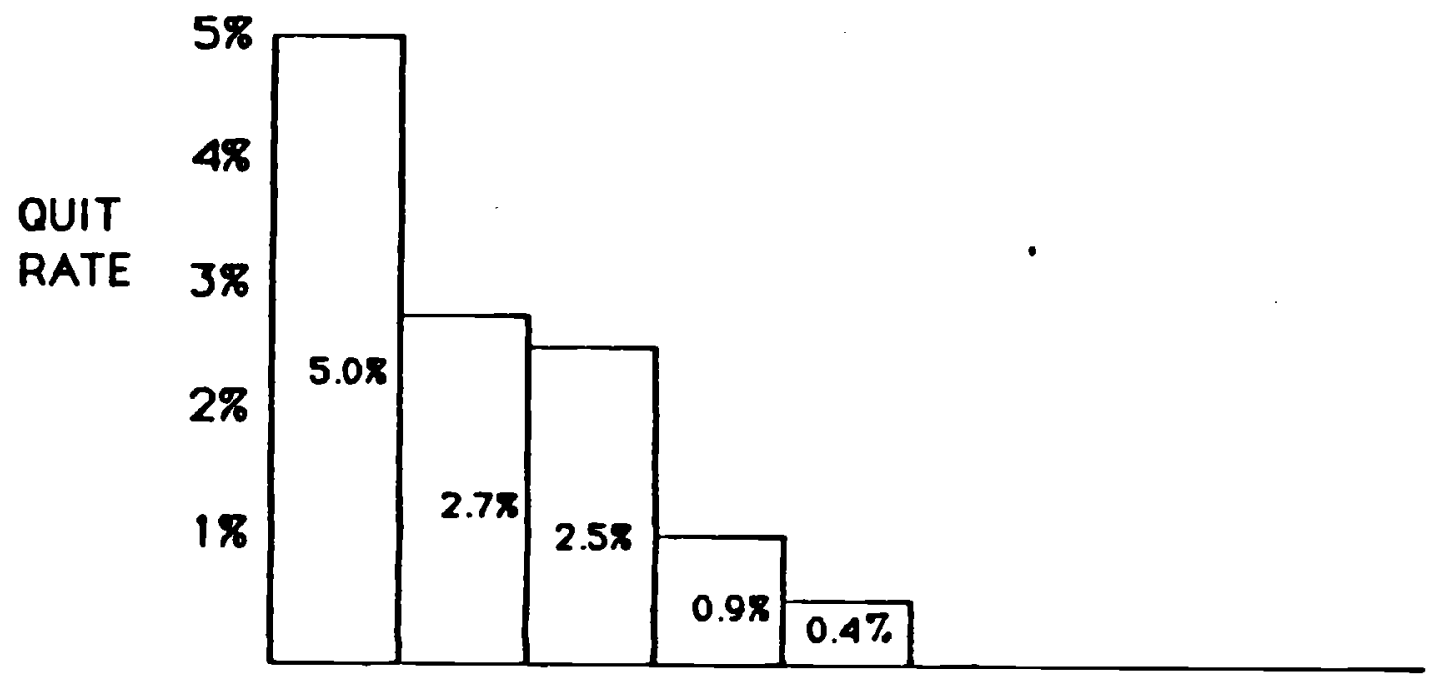

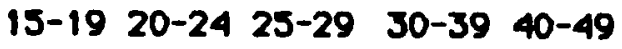

AGE

FIGURE 7 